\title{
Yay katsayısı sürekli değiştirilebilen seri elastik aktüatör tasarımı ve imalatı
}

\author{
Ömer PEKDUR ${ }^{1, *}$, Davut AKDAŞ ${ }^{2}$ \\ ${ }^{1}$ Balıkesir Üniversitesi, Mühendislik. Fakültesi, Makina Mühendisliği Bölümü, \\ Çă̆ıs kampüsü, Balıkesir. \\ ${ }^{2}$ Balıkesir Üniversitesi, Mühendislik. Fakültesi, Elektrik Elektronik Mühendisliği Bölümü, Çă̆lş \\ kampüsü, Balıkesir.
}

Geliş Tarihi (Received Date): 01.10.2018

Kabul Tarihi (Accepted Date): 14.05.2019

\begin{abstract}
Özet
Hareketli robotlarda eklem tahriki için dişli kutusuna sahip elektrik motorları yaygın olarak kullanılmaktadır. Dişli kutusu çıkışında yüksek empedans görülmektedir. Robotlarda eklem hızlarına, hareket türüne ve dişarıdan gelecek darbelere karşı eklem empedansının sürekli olarak değiştirilmesi gereklidir. Bu soruna çözüm oluşturulması için dişli kutusunun çıkışına seri olarak yay ve benzeri elastik elemanlar kullanılmış ve bunların yay katsayıları değişik yöntemlerle değiştirilmeye çalışılmıştır. Kısıtlı hareket alanlarında başarı da elde edilmiştir. Bu çalışmada daha pratik mekanik uygulamaya ve daha geniş yay katsayısı aralığına sahip eleman geliştirilmesi hedeflenmiştir. Bu amaçla hava yayı geliştirilmiş ve bu elemanın değişik yük ve basınç aralıklarında karakteristiği çıkarılmıştır. İlk deneysel bulgularda, farklı basınçlar altında seri elastik elemanin deformasyon ve yük ĕgrileri elde edilmiş, bu elamanların geniş kuvvet aralıklarında etkin kullanılabileceğini görülmüştür.
\end{abstract}

Anahtar kelimeler: Seri elastik aktüatör, hava yayı, eklem empedansı.

\section{Design and production of continuously variable series elastic actuator}

\begin{abstract}
\footnotetext{
* Ömer PEKDUR, opekdur@gmail.com, http://orcid.org/0000-0003-1392-0044

Davut AKDAŞ, akdas@balikesir.edu.tr, http://orcid.org/0000-0002-2492-5046
}

Electric motors with gearboxes are widely used for joint drive in moving robots. High impedance is observed at the gearbox output. It is necessary to continuously change the joint impedance against the joint speeds, type of movement and the impacts from the 
outside. In order to solve this problem, spring and similar elastic elements were used in series to the output of the gearbox and their spring coefficients were tried to be changed by different methods. Success was achieved in the limited range of motion. In this study, it is aimed to develop elements with more practical mechanical application and wider spring coefficient range. For this purpose, air spring has been developed and the characteristics of this element at different load and pressure ranges have been worked out. In the first experimental findings, the deformation and load curves of the series elastic elements under different pressures were obtained and it was seen that these elements could be used effectively in wide force ranges.

Keywords: Robotic foot design, robotic arm design, series elastic actuators, air spring.

\section{Giriş}

Aktüatörlerin karakteristikleri hareket oluşturmada ve kontrolünde anahtar elemanlardır. Canlılardaki hareket kabiliyetleri ve hareket esnasındaki enerji depolama özellikleri, canlılardaki ile kıyaslanabilir özellikte aktüatör olmaması nedeniyle, günümüzde gerçekleştirilen makinalarca yakalanamamaktadır. Canlıların kaslarının mekanik yapısı ve nörolojik kontrol yöntemi, özellikle eklemlerin sürekli ve gerçek zamanlı empedanslarının değiştirilebilmesi açısından, günümüz robotlarının çok ötesindedir. Günümüzdeki robot yapılarında genellikle eklemlerin konum kontrolü yapılmaktadır. Robot kolu istenen konuma geldiğinde bu konumu, dişarıdan bozucu kuvvetler uygulansa bile korur (ideal olarak sonsuz empedans durumunda) [1]. Bu yüksek empedans, motor şaftına bağlı yüksek dişli oranına sahip dişli kutusunca sağlanmaktadır. Endüstriyel robotlar için bu istenen bir durumdur, fakat çevresi ile etkileşen robotlar için eklem empedanslarının değiştirilebilir olması istenir [2]. Birçok pratik uygulamada Seri Elastik Aktüatörlerin sabit yay katsayısı veya elastisite modülü olmaktadır. Bunun başlıca sebebi, aktüatör ve seri elastik elaman için kısıtlı mekanik montaj hacim ve bağlantı şekli kısıtlamalarıdır. Sabit yay katsayısı veya elastisite modülü sabit bir eklem empedansı ortaya çıkarır. Bilindiği gibi, mekanik empedans zaman bağımlı kuvvet ile zaman bağımlı konum arasındaki dinamik ilişkiyi ifade eder. $\mathrm{Bu}$ diferansiyel ilişki doğrusal ya da doğrusal olmayan türlerden olabilmektedir [3].

Seri Elastik Aktüatörlerin etkisini oluşturabilecek farklı mekanik yapıların pratikte uygulandığını görmekteyiz. Bu elemanların tüm türevleri karakteristik olarak kinetik enerjinin depolanması ve darbe emilmesi ortak özelliklerini taşımakla birlikte farklı fiziksel prensiplerle istenen eklem empedansı elde edilmektedir. Yazılımla aktif empedans kontrolü, ataletsel sistemler ve mekanik sistem içsel özellikli olarak elastik yapıları gruplandırabiliriz.

Aktif empedans kontrolü, seri elastik elamanın davranışını kontrol sistem yazılımı ile gerçekleştirmeye (taklit etmeye) çalışmaktır [4]. Bu tür yapılarda, sistemde kullanılan sensörlerin, aktüatörlerin ve kontrol donanımının hızının, sistemin etkileşimde bulunacağı ortamdaki hız gereksinimlerinden çok daha yüksek hızlarda tepkiler verebilmesi gereklidir. Fakat mekanik darbelerin bant genişliği neredeyse sonsuz olduğu için (iki çok sert cisimin çarpışması gibi), sistem hızı ne kadar yüksek olursa olsun, bu tür darbe (impulse) kuvvetleri sistemce emilememektedir. Ayrıca, aktif empedans sistemlerinde mekanik enerji depo edilmemekte dolayısıyla enerji verimliği oldukça düşük olmaktadır. 
Ataletsel empedans kontrolünde yay ve sönümleyici olmaksızın sadece kütle kinetik enerjinin depolanmasında kullanılmaktadır. Burada cayro elemanı depoladı̆̆ 1 dönü enerjisi ile robotları dengede tutmada veya Formula 1 gibi yarış otomobillerinin yönlendirilmesinde ve teknelerin dalgalı denizlerde sarsıntılarını azalmada kullanılmaktadır [5 ve 6]. Bu tür mekanik yapılar oldukça ağır, büyük hacimlerde, özel imalat gerektiren yapılarda ve pahalı olmaktadırlar.

İçsel özellikli elastik yapılar aktüatörlerden sonra seri olarak bağlanmışlardır ve yükleri hareket ettirmede kullanılmaktadırlar. Elastik elamanlar mekanik özellikleri gereği tüm pratik bant genişliklerinde kuvvetlerle etkileşime girebilmekte ve bunlardan gelen enerjileri belirli oranlarda içlerinde depolayabilmektedirler [7]. Göreceli olarak küçük hacimlerde, ağırlıklarda ve düşük maliyetlerde olmaktadırlar. $\mathrm{Bu}$ tür sistemler yay katsayıları sabit ya da değişen türlerde olabilmektedirler. Uygulamanın özelliğine bağlı olarak bir yapı tercih edilmektedir. Bu çalışmada geliştirilmekte olan Seri Elastik Aktüatör nihai olarak yürüyen robotlarda kullanılması için araştırma yapıldığından dolayı sistem yay katsayısının robot uzvunun hareketine bağımlı olarak sürekli ve gerçek zamanlı olarak değiştirilmesi hedeflenmiştir. Canlılar yürüme hareketleri esnasında sürekli olarak kaslarının yay katsayılarını değiştirmektedirler [8]. Örneğin bir hayvanın ayağı yere bastığında yüksek, ayağı havada ileri doğru salınımda olduğu zaman ise düşük empedans değerlerine sahiptir.

Bu çalışmada canlılar örnek alınarak, aktüatöre seri bağlı elemanın yay katsayısını gerçek zamanlı değiştirmeye imkân sağlayacak seri elastik aktüatör tasarımı ve deneylerle temel karakteristiği çıkartılan aktüatör verileri sunulmuştur.

Bu makalede çalışmanın temelini oluşturan ve araştırmacılarca geliştirilen, temel testleri gerçekleştirilen yaylı bir seri elastik aktüatör sistemi ikinci bölümde tanıtılmıştır. Üçüncü bölümde, yay katsayısının sürekli değiştirilmesine imkân sağlayacak ve kendi sistemimizde kullanılan hava yayı karakteristiği özellikleri verilmiştir. Dördüncü ve beşinci bölümlerde iki farklı tasarım modeli ortaya konulmuştur. Son olarak bulgular ve sonuçlar sunulmuştur.

\section{Seri elastik aktüatörler}

Seri elastik aktüatörler içsel elastik yapıya sahip olduklarından, özellikle darbe şeklindeki yüklerin enerjilerinin emilmesinde diğer yapılara göre avantajlara sahiptir [9 - 23]. Elastik elemanlar, çıkışı yüksek empedansa sahip olan tahrik elemanlarına (yüksek dişli oranlı elektrik motorları) seri olarak bağlanmaktadır. Belirli empedans değerlerinin her zaman yakalanması için, elastik elemanlar her zaman ön yükleme altında olmak zorundadır. Bunun için aşağıda şekil 1 de gösterilen birbirleri ile zıt çalışan (antagonistik) yapı ve değişik türevleri kullanılmaktadır. Bu şekilde iki adet yay elemanın motor1 ve motor2 tarafindan belirli oranlarda zit veya birbirine göre aynı yönde ve farklı kuvvetlerde sürülmesi ile istenen çıkış empedansı sağlanmaktadır. Bu basit yapının dezavantajları eklem torkunun tek bir motorun azami torkundan daha fazla olamaması ve yayın uzama sinırlarında tork elde edilememesidir [24]. 


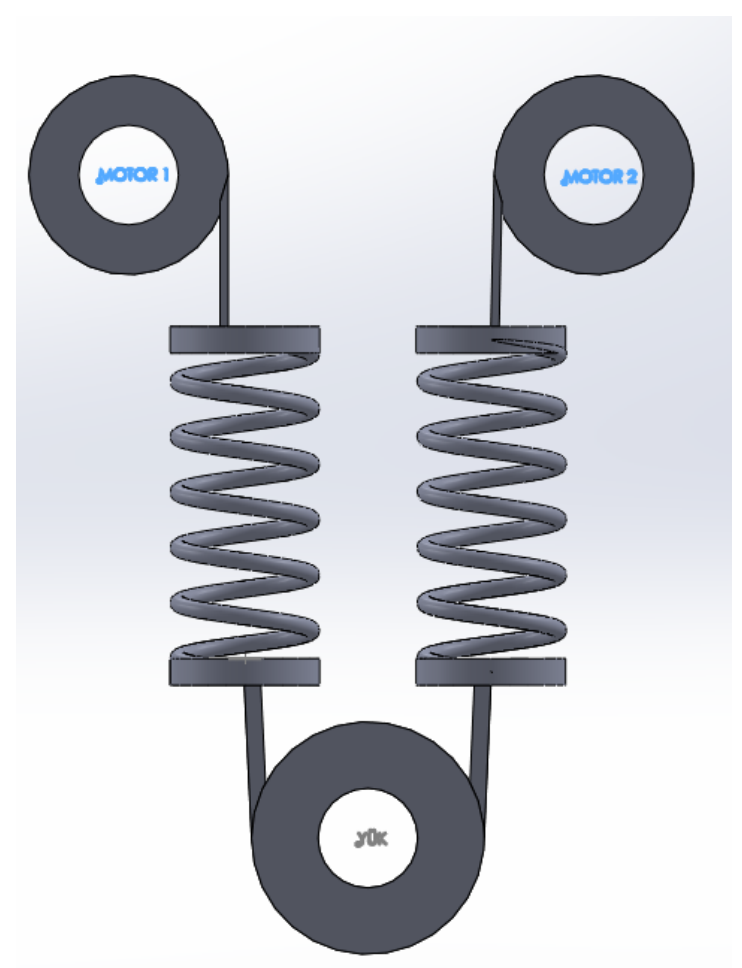

Şekil 1. SEA'nın şematik gösterimi.

Literatürde her bir yayın ayrı ayrı veya birlikte başka yay elemanlarına bağlanması ile motorların tork-yay elemanlarının hareket sınırları geliştirilmiştir [25]. Başka bir çalışmada ise Şekil 1'dekinden farklı olarak her bir motora sağlı-sollu iki adet yay elemanı bağlandığı ve bunun yay davranışını olumlu geliştirdiği sunulmuştur [26]. Fakat her bağlantı şeklinde sürülen eklem empedansı ve eklem konumu motorların birbiri ile senkronize çalışmasıyla gerçekleşmekte ve eklem konumu ve eklem empedansı aynı motor çifti ile sağlanmaktadır. Bazı çalışmalarda üçüncü bir motor kullanılarak eklem konumu ve eklem empedansı birbirinden bağımsız hale getirilmiştir [27 ve 28]. Bu çalş̧malarda kısıtlı iyileştirmeler elde edilmesine rağmen yapıların büyüklüğü ve ilave motor gereksinimi mobil robot uygulamalarında uygulanmalarını güçleştirmektedir.

Bu makaleye konu olan çalı̧̧malarımız, yukarıda bahsi geçen çalışmalar incelendikten sonra, ön sıkıştırmalı yayların dişli kutusuna sahip bir motor tarafından sürülebilmesini incelemekle başlamıştr. Burada elde edilen tecrübeler 1şığında üçüncü bölümde bahsedilen havalı elastik elamanın tasarımı gerçekleştirilmiştir.

Aktüatörün çıktı kuvveti yayın sıkışmasına bağlıdır ve Hook Kanunu ( $F=k . x)$ temeline dayanmaktadır. Yayın sıkıştırılması bir sensör yardımıyla hesaplanır. SEA'da kullanılan yayın sabiti bilindiği için yayın sıkışma miktarına göre çıktı kuvveti otomatik olarak hesaplanır. Bu hesaba göre motora sinyal gönderilerek kuvvetin kontrol edilmesi sağlanır. Şekil 2 seri yay elemanların kullanımı ile gerçekleştirilen aktüatörü göstermektedir. Şekil 3'te ise bu seri elastik aktüatörün çalışması esnasında kuvvet yönlerine bağlı olarak yay elemanlarının şekil değiștirmeleri gösterilmektedir. Bu çalışmada yaylar, uygulanan kuvvetle doğrusal olarak şekil değiş̧irmektedir. Yay katsayısı ve yaylara uygulanan ön gerilme, robot tarafindan manipüle edilecek cisimler (eğer bu sistem robot kollarında kullanılırsa) sadece benzer boyutlarda ve ağırlıklarda 
olduğu durumlarda verimli kullanım olacağı görülmüştür. Çünkü yayların ön gerilmelerinin değişimi el ile yapılmaktadır. Ayrıca bu tasarımda aktüatörün bağlı olacağ1 robot yapının konum ve empedansının birlikte değiștiği görülmüştür. Dışarıdan gelebilecek bozucu kuvvetler eklem konumunu değiştirmiştir. Sonuç olarak eklem konum ve eklem empedansı bu tasarımda birbirinden bağımsız olarak korunamamıştır. Ayrıca mekanik yapı sabit robot kolları için bir alternatif aktüatör yapısı oluştursa da, yürüyen robotlar için bu yapı oldukça büyük ve ağırdır. Özellikle mobil robotun tüm elektronik ve mekanik elemanları ve enerji depolama birimleri üzerinde taşıma olasılığı düşünüldüğünde, seri elemanın, hâlihazırda oldukça ağır olan motorlara çok fazla ilave ağırlık oluşturmaması gerekir. Bu çalışma sonucunda hava yayının daha iyi bir alternatif olacağı sonucuna varılmıştır.

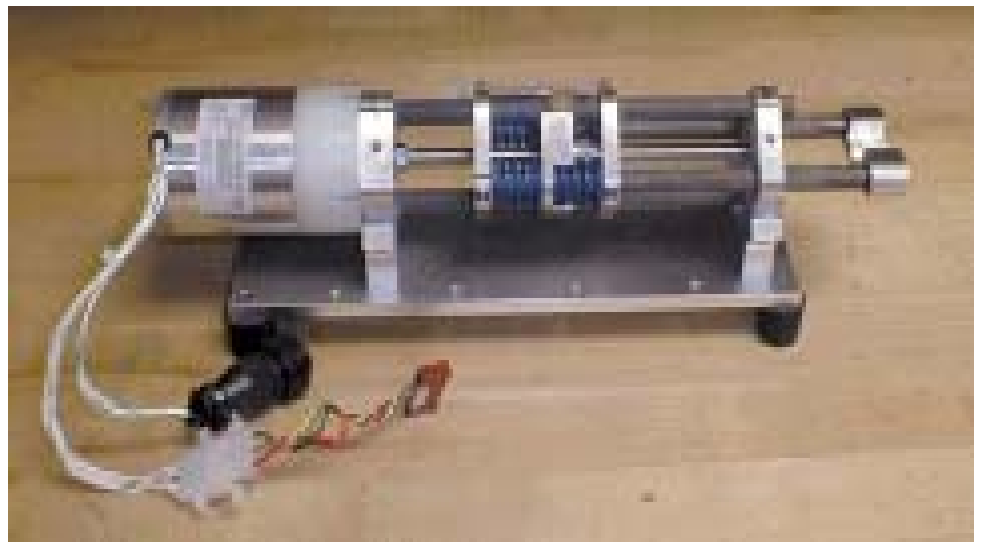

Şekil 2. Araştırmalarımızın ilk aşamasında geliştirilen elektrikli seri elastik aktüatör.

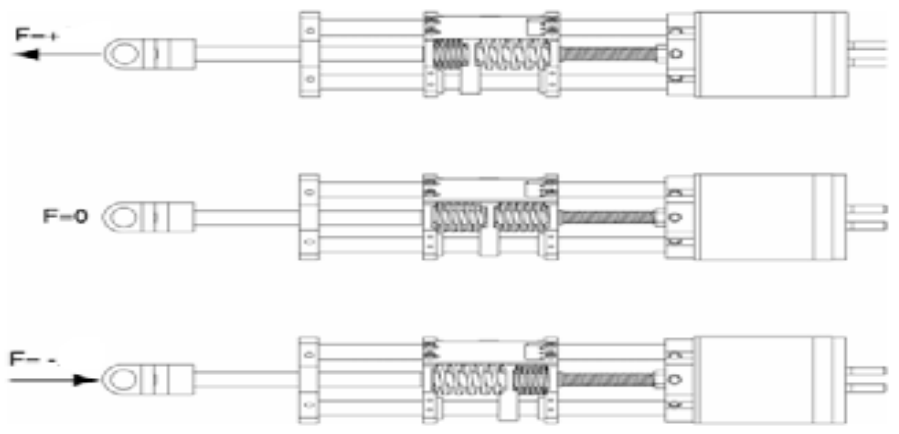

Şekil 3. Seri elastik aktüatörde oluşan kuvvetler ve yönleri.

\section{Hava yayı}

Hava yayları genellikle titreşimli yerlerde titreşim sönümleyici olarak kullanılırlar. En çok kullanıldığı yerler otomobil, kamyon, otobüs, tren gibi araçlar ile titreşimli çalışan makinelerdir. Hava yayları birçok biçimde imal edilmektedirler. Bağlandıkları yerlere, çalışma koşullarına ve maruz kaldıkları kuvvetlerin büyüklüklerine göre hava yaylarının şekil ve büyüklükleri değişmektedir. Hava yaylarının çalışma prensibi (içerisinde hava veya azot gazı bulunabilir.) kapalı hacimdeki gazların elastik davranışlarının yay olarak kullanılmasına dayanmaktadır. Hava yayları progresif yay karakteristiğine sahiptirler. Hava yayının yay sabiti içindeki hava basıncının değişimine bağlı olarak değişmektedir. 
Hava yayının bir diğer önemli yanı ise artan yük ile hava yayının artan iç basıncı neticesinde yay katsayısının artması ve azalan işletme basıncında ise uygun bir şekilde azalmasıdır. Örnek bir hava yayının yay karakteristiği Șekil 4'te görülmektedir [29 ve 30]. Bu şekilde hava yayının doğrusal olmayan karakteristiğe sahip olduğu görülmektedir. Literatürde de bu tür kuvvet-konum ilişsisinin seri elastik aktüatörlerden istenen bir özellik olduğu belirtilmektedir. Özellikle zıplama hareketi yapan robotlar üzerine çalışma yapan araştırmacılar [31] bu karakteristiğin ani darbelerin emilmesi için gerekli olduğu sonucuna varmışlardır. Bizim nihai amacımız, seri elastik aktüatörü yürüyen robotlarda kullanılması için geliştirmektir. Yürüme esnasında zemin ile ayakaltı arasında ani kuvvet aktarımı olacağından aşağıda yer alan şekil 4'teki hava yayı karakteristiğinin amaca uygun olduğu görülmektedir.

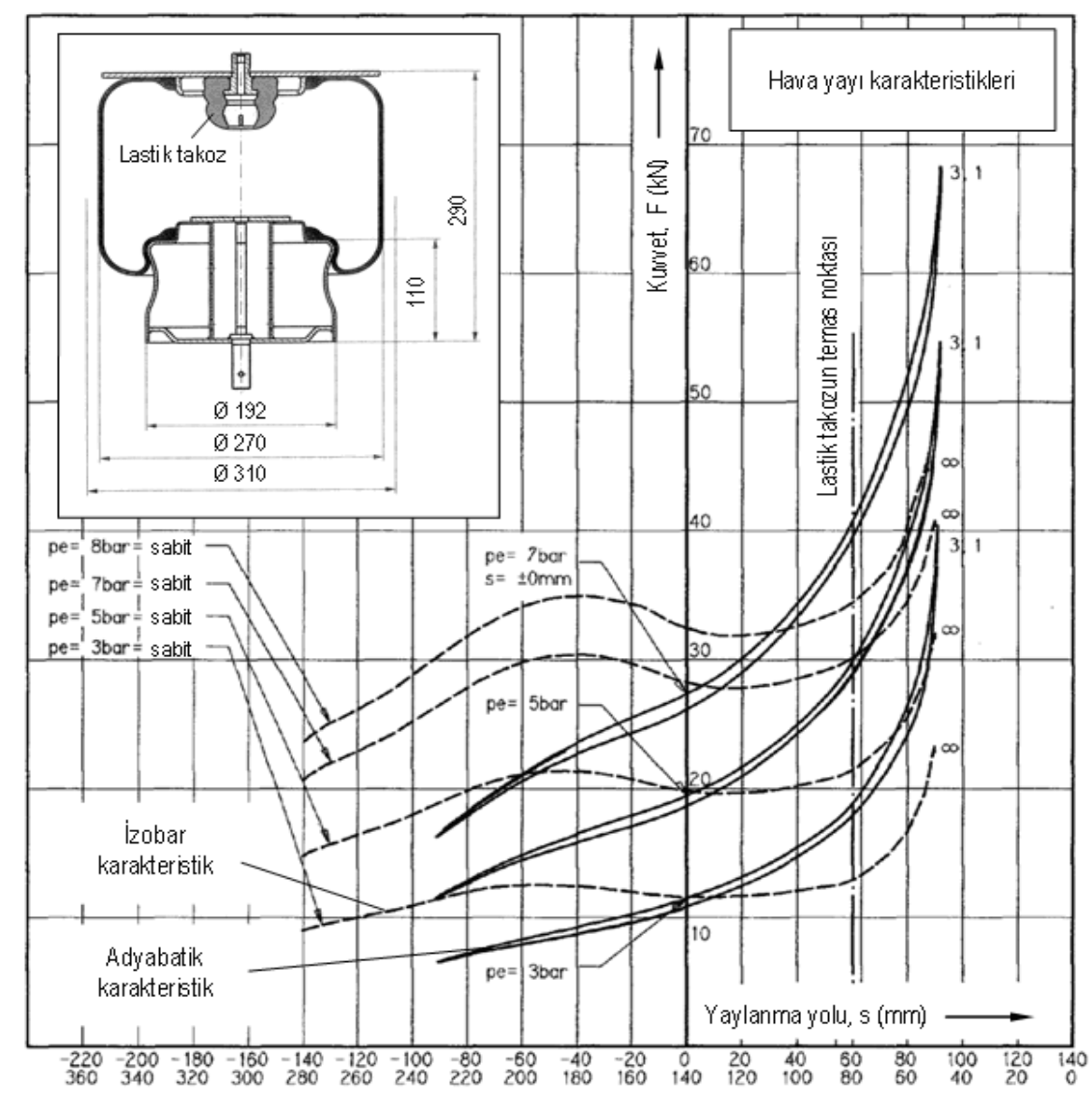

Şekil 4. Hava yayı karakteristiği.

Literatürde hava yaylarının doğrudan robot eklemlerini sürdükleri uygulamalarda vardır. Bu tür uygulamalarda havalı eleman doğrudan aktüatörün kendisi olmaktadır ve yapay kas olarak adlandırılmaktadır. En yaygın kullanılan tasarım McKibben yapay kasıdır [32]. Yapay kaslar kendi içyapılarında yüksek sürtünmeye sahiptir. Ayrıca çalışmaları esnasında histeresis ve ölü bölge konum ve empedans kontrolü yapılmasını oldukça güçleştirmektedir. Yapay kaslar parçalı (pleated) yapılarak bu olumsuzluklar azaltılmaya çalış1lsa da önemli bir ilerleme kaydedilememiştir [33 ve 34]. Bu sebeplerden dolayı seri elastik aktüatörler pratik uygulamalarda yer almaktadır ve eklem empedans kontrolünde başarılı sonuçlar vermektedir [35]. 


\section{Deneysel hava yayı tasarımı}

Hava yaylarının imalinde kullanılan lastiğin boyutları ve kuvvetlere karşı dayanım değeri o hava yayının kullanılacağı kuvvet aralığını belirlemektedir. Eğer robot düşük kuvvetlerin etkisi altında çalışacaksa bu robotta kullanılacak SEA'daki hava yayının boyutları ve dayanım değerleri de ona göre düşük olacaktır. Yüksek ise hava yayının değerleri de yüksek olacaktır. Balıkesir Üniversitesi'nde gerçekleştirilen insansı robot çalışmasında [36], robot eklemlerinin tork değerlerinin gerçekleştirilen hareket esnasında birbirlerinden farklı olduğu gösterilmiştir. Ayrıca genel amaçlı tek bir yay tasarımının robotun tüm eklemleri ile boyutsal uyumu da genelde mümkün olmamaktadir.

$\mathrm{Bu}$ nedenle bu çalışmada iki farklı SEA tasarımı üzerinde çalışılmıştır. Tasarlanan SEA'lardan biri düşük kuvvetler de çalışmakta diğeri ise daha büyük kuvvetlerde çalışabilmektedir.SEA'da kuvvet kontrolünün yapılabilmesi için yay sabitinin çok iyi bilinmesi gerekmektedir. Hava yaylarının yay sabitinin iç basıncına göre değişmesinden dolayı öncelikle tasarımda kullanılacak yayların değişik iç basınçlardaki yay sabiti karakteristiği çıkarılmıştır.

\subsection{Birinci tasarım; düşük güçler için}

Piyasada satılan hava yayları genelde çok yüksek yükler altında çalıştığ 1 için bu çalışmada düşük yükler altında çalışabilecek hava yayı ihtiyacına yönelik olarak hava yayları imal edildi.

Piyasada sönümleyici olarak çalışan ve içi silikon dolu olan bir körük alınarak tasarımda kullanılacak hava yayına dönüştürülmüştür. Körüğün içindeki silikon boşaltılmış, normal yay alınmış ve alın kısmına iç basıncı dışarıdan değiştirebilmek için delik açılmıştır. Kullanılan körük Şekil 5'da gösterilmiştir.

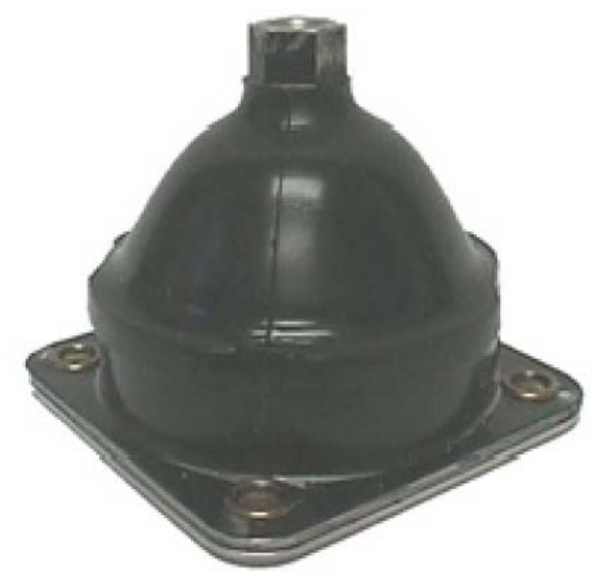

Şekil 5. Hava yayına dönüştürülen körük.

Hava yayına dönüştürülen körüğün öncelikle hazırlanan deney düzeneğinde değişik iç basınçlarda sahip olduğu yay sabiti çıkarılmıştır. Yay karakteristiğinin çıkarılması için kullanılan düzenek Şekil 6'da ve çalışma sonucu iç basınç kuvvet değerleri Tablo 1'de ve Şekil 7'de görülmektedir. 

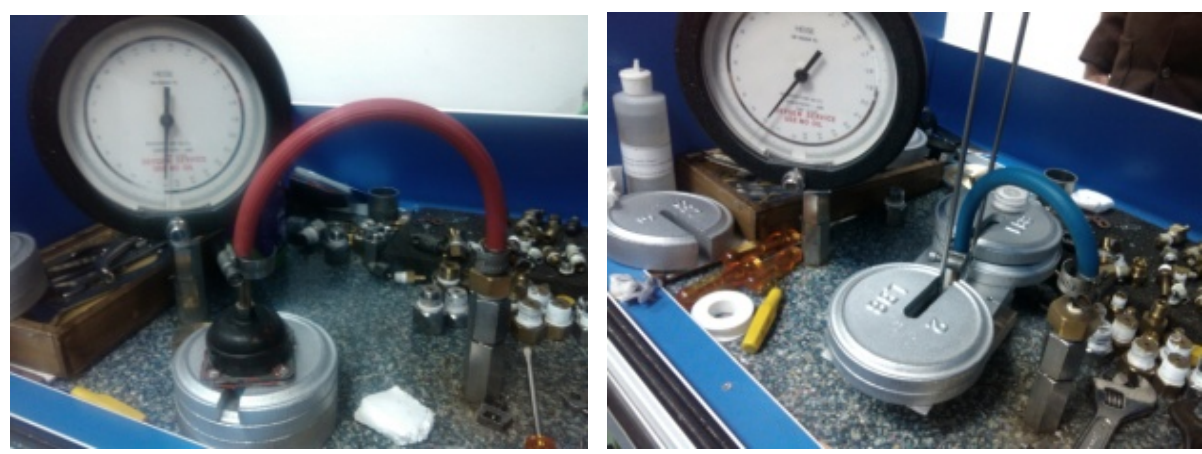

Şekil 6. Yay karakteristiği çıkarma düzeneği.

Tablo 1. İç basınç, kuvvet ve çökme değerleri.

\begin{tabular}{|c|c|c|c|c|c|}
\hline \multirow{2}{*}{$\begin{array}{c}\text { Basınç } \\
\text { (Bar) }\end{array}$} & \multicolumn{3}{|c|}{ Çökmeye Bağlı Ăğlı Miktarı $(\mathrm{Kg})$} & Yay Katsayıs1 \\
\cline { 2 - 6 } & $5 \mathrm{~mm}$ & $10 \mathrm{~mm}$ & $15 \mathrm{~mm}$ & $20 \mathrm{~mm}$ & $\mathrm{~N} / \mathrm{m}$ \\
\hline 0,5 & 2,3 & 4,58 & 6,7 & 8,82 & 2923 \\
\hline 0,4 & 2,13 & 4,05 & 5,98 & 7,8 & 3145 \\
\hline 0,3 & 1,97 & 3,74 & 5,5 & 7,18 & 3407 \\
\hline 0,2 & 1,71 & 3,3 & 4,89 & 6,52 & 3708 \\
\hline 0,1 & 1,38 & 2,75 & 4,28 & 5,85 & 4264 \\
\hline
\end{tabular}

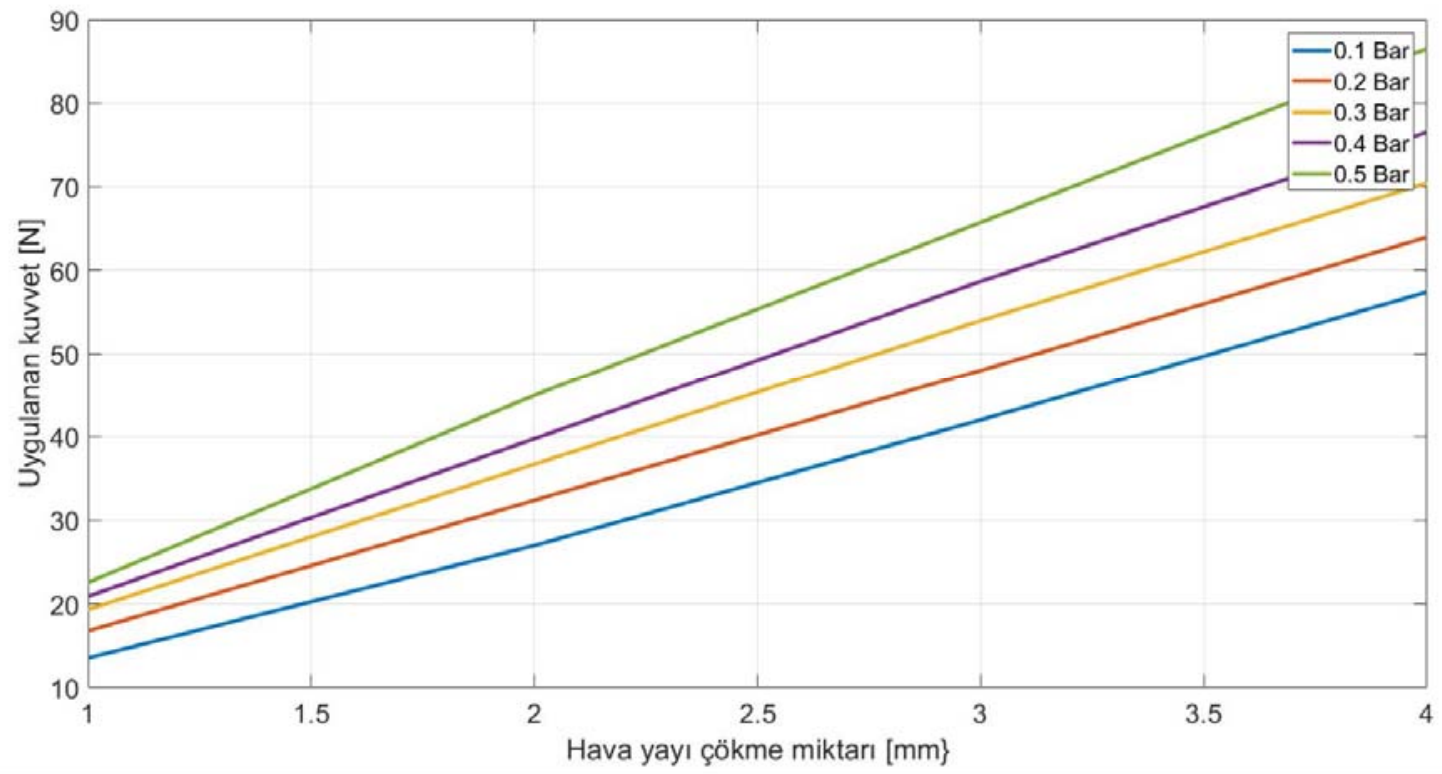

Şekil 7. İç basınç, kuvvet ve çökme değerleri.

Gerçekleştirilen deneylerde hava yayına 0.1 Bar'dan 0.5 Bar'a kadar basınçlı hava verilmiştir. Her farklı basınç değerinde $5 \mathrm{~mm}, 10 \mathrm{~mm}, 15 \mathrm{~mm}$ ve $20 \mathrm{~mm}$ çökme değeri için uygulanması gerekli kuvvet değeri ölçülmüştür. Tablo 1 ve Şekil 11 bu deneylerin bulgularıdır. Tablo 1 de hava yayının iç basıncının değişmesiyle birlikte yay katsayısı değerinin de değiştirilebildiği gösterilmiştir. Bu SEA eğer bir robotun parmaklarını 
kontrol etmede kullanılacaksa, tutma kuvveti aktüatörün içsel karakteristiği olarak cisimleri yumuşak veya daha sert kavrama olanağı sağlayacaktır.

Hava yayının karakteristiği çıkarıldıktan sonra imal edilecek SEA'nın tasarımı gerçekleştirilmiştir. Tasarlanan SEA Şekil 8'de görülmektedir.

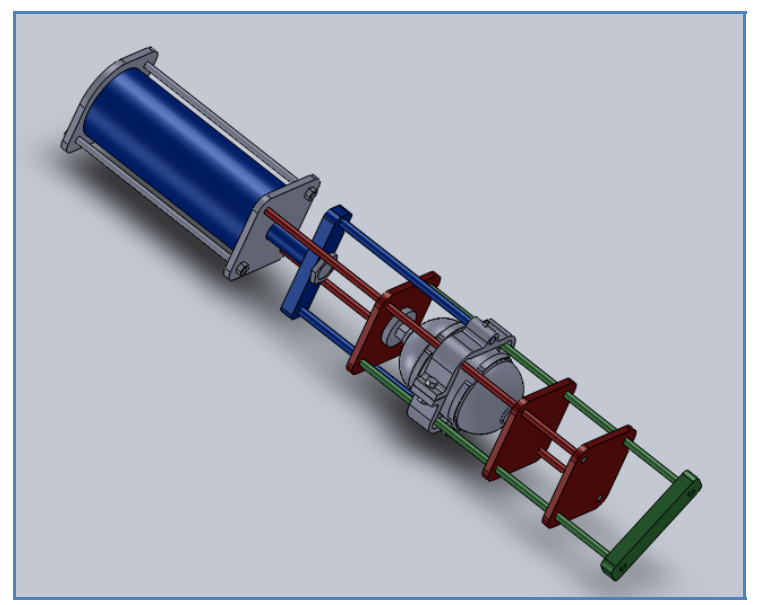

Şekil 8. Tasarımı yapılan SEA.

Tasarımda hareketi vermesi için hidrolik piston kullanılmıştır. Yay olarak sırt sırta monte edilmiş iki adet eşit hava yayı (şekil 5'deki) kullanılmıştır. Tasarımı gerçekleştirilen SEA'nın imalat parçaları tasarıma uygun olarak imal edilmiş ve daha sonra parçaların montajı yapılmıştır. İmalatı gerçekleştirilen SEA'nın parçaları Şekil 9'te ve montaj işlemi gerçekleştirilmiş SEA Şekil 10'da görülmektedir.

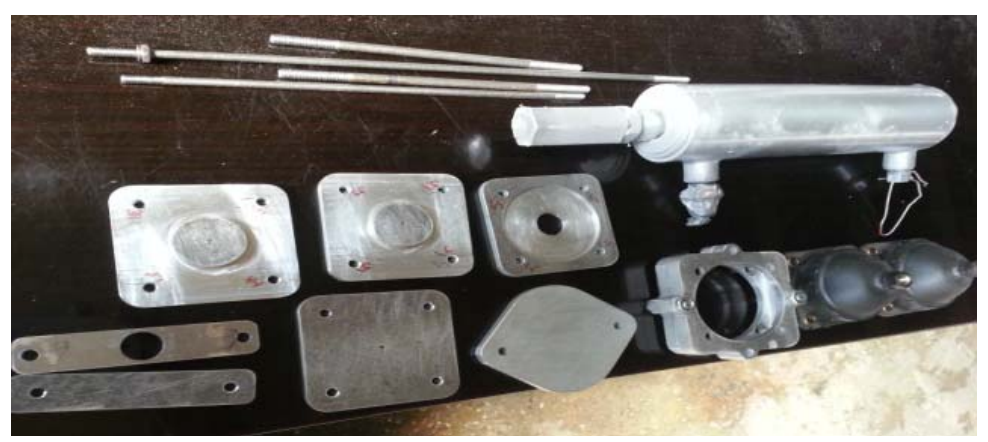

Şekil 9. İmal edilen parçalar. 

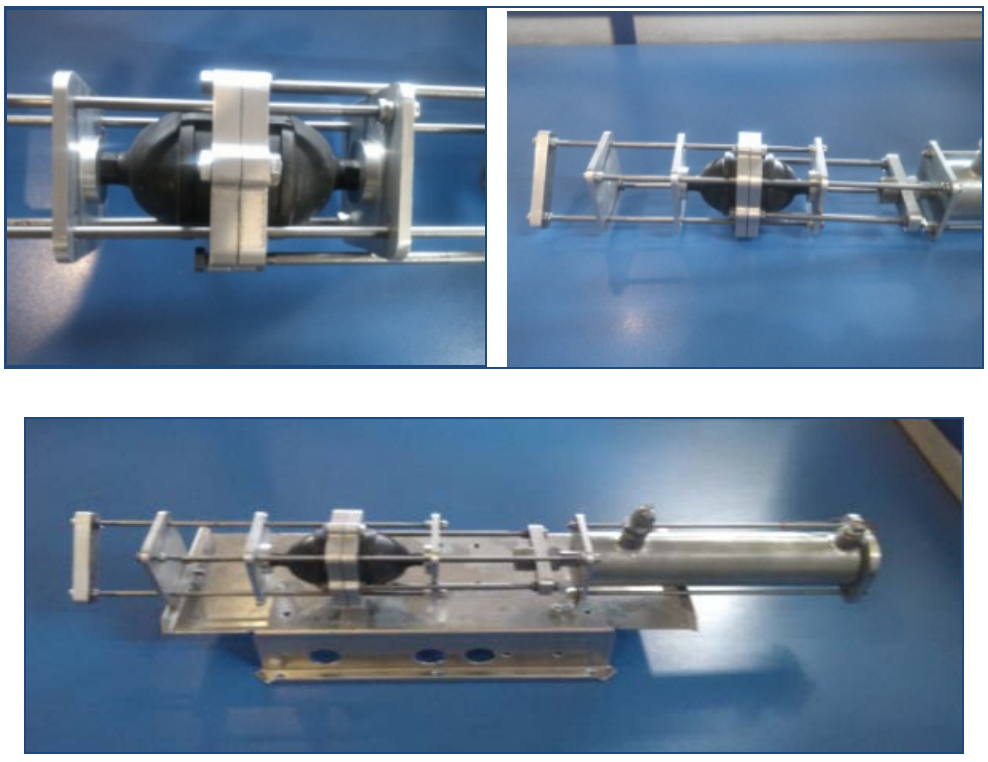

Şekil 10. Montajı tamamlanan SEA.

\section{2. İkinci tasarım; yüksek güçler için}

Daha büyük yükler altında çalışabilecek ikinci SEA tasarımı içinde öncelikle hava yayı imalatı yapılmıştır. Hava yayı için piyasada satılan bir körük alınmış ve körük kesilerek lastiği imal edilecek hava yayında kullanılmıştır. Tasarlanan hava yayı Şekil-11'de gösterilmiştir.
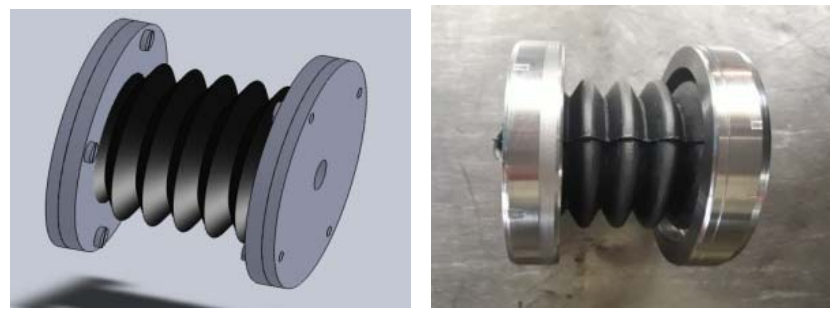

Şekil 11. Tasarımı yapılan hava yayı.

Daha sonra yayın yay sabiti karakteristiğinin çıkarılması için deney düzeneği hazırlanmış ve yay ölçme tezgâhında deneyleri yapılarak değerler çıkarılmıştır. Şekil 12 'da deney düzeneği görülmektedir.
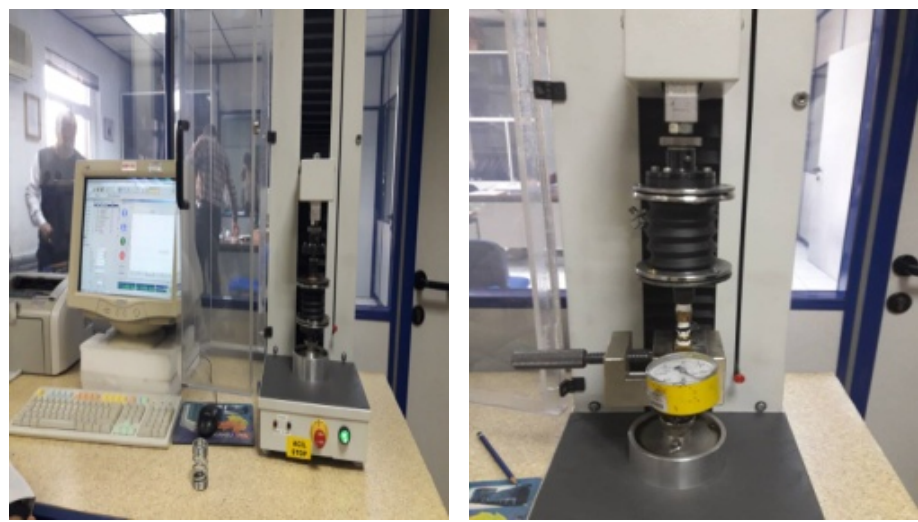

Şekil 12. Deney düzeneği. 
Yapılan deneyler sonucu imal edilmiş olan hava yayının yay sabiti karakteristiği çıkarılmıştır ve Tablo'2 deki sonuçlar elde edilmiştir. Tablo 2'deki değerler Tablo 1'deki değerlere benzer olarak, azalan basınç değerleriyle elastik elemanın yay katsayısının azaldığını (beklenildiği gibi) göstermiştir. Şekil 13 ve 14'de bu hava elemanın tasalanan montaj taslağı gösterilmiştir. Hava yaylarının içinden boru şeklinde mil geçmektedir. Sızdırmazlık o-ring ve keçelerle sağlanmaktadır. Hava yaylarının iç basınçları milin yayların içinde kalan kısımlarına açılan deliklerle değiştirilmektedir.

Tablo 2. İlk üç deney değerleri.

\begin{tabular}{|c|c|c|c|c|c|}
\hline \multirow{2}{*}{$\begin{array}{c}\text { Test } \\
\text { Numarası }\end{array}$} & \multirow{2}{*}{$\begin{array}{c}\text { Yay Katsayis } 1 \\
\mathrm{~N} / \mathrm{m}\end{array}$} & \multicolumn{2}{|c|}{ Başlangıç } & \multirow[b]{2}{*}{$\begin{array}{c}\text { Basılan } \\
\text { Mesafe (mm) }\end{array}$} & \multirow[b]{2}{*}{$\begin{array}{l}\text { Kuvvet } \\
(\mathrm{N})\end{array}$} \\
\hline & & $\begin{array}{c}\text { Yay Boyu } \\
(\mathrm{mm})\end{array}$ & $\begin{array}{l}\text { İç Basınç } \\
\text { (mbar) }\end{array}$ & & \\
\hline \multirow{7}{*}{1} & \multirow{7}{*}{5340} & \multirow{7}{*}{90} & \multirow{7}{*}{350} & 5 & 33,2 \\
\hline & & & & 10 & 57 \\
\hline & & & & 15 & 80,8 \\
\hline & & & & 20 & 113,3 \\
\hline & & & & 25 & 148 \\
\hline & & & & 30 & 171 \\
\hline & & & & 35 & 185 \\
\hline \multirow{7}{*}{2} & \multirow{7}{*}{5060} & \multirow{7}{*}{87} & \multirow{7}{*}{300} & 5 & 29,4 \\
\hline & & & & 10 & 50 \\
\hline & & & & 15 & 74 \\
\hline & & & & 20 & 105 \\
\hline & & & & 25 & 130,6 \\
\hline & & & & 30 & 146 \\
\hline & & & & 35 & 186,5 \\
\hline \multirow{8}{*}{3} & \multirow{8}{*}{4204} & \multirow{8}{*}{85} & \multirow{8}{*}{250} & 5 & 22,3 \\
\hline & & & & 10 & 42,4 \\
\hline & & & & 15 & 65,1 \\
\hline & & & & 20 & 89,7 \\
\hline & & & & 25 & 108,6 \\
\hline & & & & 30 & 127,4 \\
\hline & & & & 35 & 164,5 \\
\hline & & & & 40 & 209 \\
\hline
\end{tabular}

\begin{tabular}{|c|c|c|c|c|c|}
\hline \multirow[b]{2}{*}{$\begin{array}{c}\text { Test } \\
\text { Numaras } 1\end{array}$} & \multirow[b]{2}{*}{$\begin{array}{c}\text { Yay Katsayis } 1 \\
\mathrm{~N} / \mathrm{m}\end{array}$} & \multicolumn{2}{|c|}{ Baslangic } & \multirow[b]{2}{*}{$\begin{array}{c}\text { Basilan } \\
\text { Mesafe } \\
\text { (mm) }\end{array}$} & \multirow[b]{2}{*}{$\begin{array}{l}\text { Kuvvet } \\
(\mathrm{N})\end{array}$} \\
\hline & & $\begin{array}{c}\text { Yay Boyu } \\
\text { (mm) }\end{array}$ & $\begin{array}{l}\text { İç Basınç } \\
\text { (mbar) }\end{array}$ & & \\
\hline \multirow{8}{*}{4} & \multirow{8}{*}{4046} & \multirow{8}{*}{81} & \multirow{8}{*}{200} & 5 & 18,1 \\
\hline & & & & 10 & 36,1 \\
\hline & & & & 15 & 55,4 \\
\hline & & & & 20 & 75,8 \\
\hline & & & & 25 & 96 \\
\hline & & & & 30 & 114,9 \\
\hline & & & & 35 & 139,5 \\
\hline & & & & 40 & 169,6 \\
\hline
\end{tabular}


Tablo 2. (Devami).

\begin{tabular}{|c|c|c|c|c|c|}
\hline \multirow{8}{*}{5} & \multirow{8}{*}{3812} & \multirow{8}{*}{75} & \multirow{8}{*}{150} & 5 & 18,2 \\
\hline & & & & 10 & 35,7 \\
\hline & & & & 15 & 54,3 \\
\hline & & & & 20 & 72,3 \\
\hline & & & & 25 & 90,8 \\
\hline & & & & 30 & 113,5 \\
\hline & & & & 35 & 142,3 \\
\hline & & & & 40 & 185,9 \\
\hline
\end{tabular}

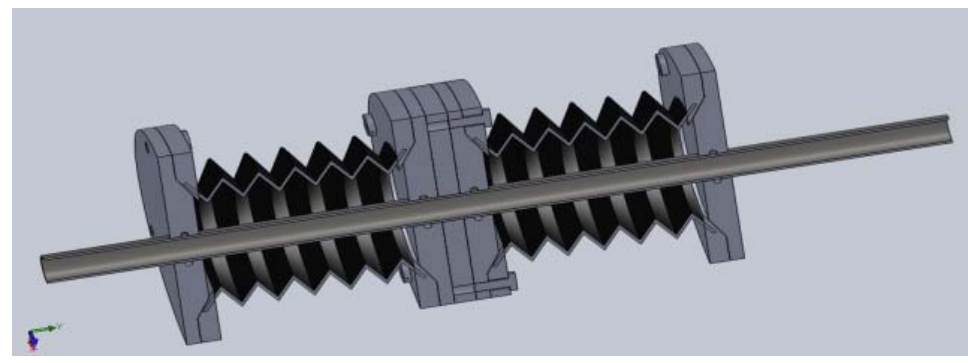

Şekil 13. Monte edilmiş hava yayı.

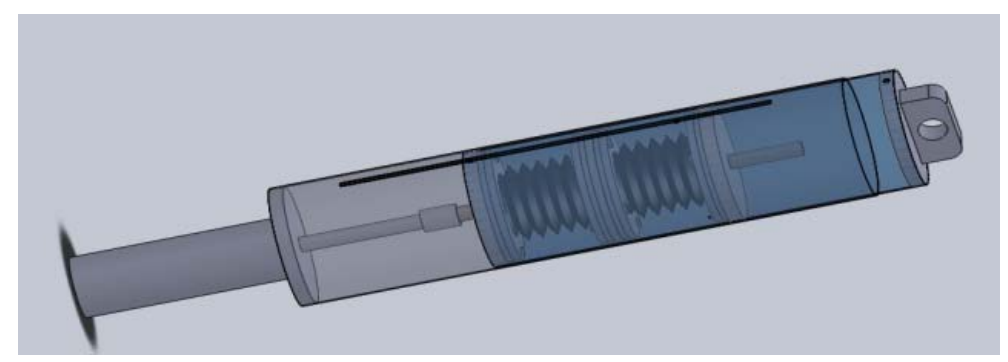

Şekil 14. Yüksek güçlü seri elastik aktüatörün taslak tasarımıdır.

\section{Sonuçlar ve öneriler}

Çalışmamızın başlangıcında taranan literatür'den çıkartılan sonuç, gelişen robot teknolojisi ile insan makine etkileşiminin arttığı ve bunun sonucunda hem insan hem robot için güvenlik tedbirlerinin alınması gerektiğidir. Ayrıca ayaklı robotların da çok sayıda araştırmacı tarafından geliştirilmekte olması ve deneylerde değişik hızlarda yürüyen robot ayaklarının bilinmeyen zemin yüzeyleri ile darbeli etkileşimi SEA'ları gerekli kılmaktadır. Özellikle darbe (impulse) şeklinde gelen kuvvetlerin, aktüatör tarafından emilmesi ve enerji olarak depolanması robotun bilinmeyen yüzeylerle etkileşiminde eklem konum kararlılığını artırırken, SEA'da depolanan enerjinin geri kullanımı ile robotun hareket verimliliği de artırılmış olacaktır. Tüm canlılarda bu mekanizmalar vardır ve bu nedenle canlıların hareketleri her hareket koşulu altında en verimlidir.

Robot eklemlerinde farklı tork (kuvvet) gereksinimleri ortaya çıkmaktadır. Örneğin robot elleri ve ayakları için aynı aktüatörü kullanmak mümkün değildir (boyut ve kuvvet açısından). Ayrıca seri elastik aktüatörün robot eklemlerinde ortaya çıkaracağı empedans değerlerinin, canlılarda olduğu gibi, robot ekleminin hareketine bağımlı 
olarak değiştirilmesi gerektiği literatürde sunulmuştur. Bu nedenle iki farklı kuvvet aralığı için tasarım yapılması öngörülmüştü. Seri elastik aktüatörlerin karakteristiğini belirleyecek olan hava yaylarını hazır bulmak mümkün olmamıştır. Deneysel amaçlarla geliştirilen hava yayları ya çok iyi üretim imkanları olan araştırma kurumlarında geliştirilmiş veya bu çalışmada olduğu gibi farklı amaçlarla kullanılan ürünleri hava yaylarına dönüştürme yoluna gidilmiştir. Gerçekleştirilen iki hava yayı için, sönümleyici olarak kullanılan iki farklı körük türü kullanılmıştır. Test düzenekleri ile hava yayı elamanlarının karakteristikleri çıkartılmıştır. Tablo 1 ve Tablo 2 yaylar için elde edilen verileri içermektedir. İki tablo kıyaslandığında değişen iç basınçla birlikte, hava yayının yay sabitinin değiştirilebildiği görülmüştür. İkinci tasarım için tabloda 2'de sadece 0.35 Bar değerine kadar veriler sunulmuştur. 0.3 Bar yüksüz iç basınç değeri için ilk tasarım $3407 \mathrm{~N} / \mathrm{m}$, ikinci tasarım ise $5060 \mathrm{~N} / \mathrm{m}$ yay katsayısına sahiptir. Hava yaylarının doğrusal olmayan karakteristiği nedeniyle, iki hava yayı arasındaki oran eşit değişmemektedir. İki hava yayı da artan basınç değerleriyle doğrusal olmayan bir şekilde artan yay katsayısı karakteristiği göstermektedir. Özellikle ikince hava yayında aratan basınç neredeyse logaritmik konum-kuvvet değişimi göstermektedir. Üçüncü bölümde bahsedildiği gibi, doğrusal olmayan davranış canlıların kas sistemlerinde görülmektedir ve yürüyen robotlarda istenen bir durumdur. Bu sayede darbelerin aktüatörce emilmesi sağlanmaktadır.

Şekil 8 ve 14 de verilen seri elastik aktüatörler olası bir tasarımı göstermektedir. Bu tasarımlar oldukça uzundur. Ayak ve gövde eklemlerini doğrudan sürmek için uygundur fakat parmak ve benzeri küçük uzuvları bu aktüatörlerle doğrudan sürmek fiziki olarak mümkün değildir. Bu durum canlılar içinde benzerdir ve canlılardaki tendonların işlevini yerine getirecek kablo sistemleri aktüatöre bağlanarak fiziki olarak küçük uzuvların sürülmeleri ve eklem empedanslarının da ayarlanabilmesi mümkündür.

Çalışmamızda seri elastik aktüatörün istenildiği gibi yay katsayısı değişebilen ve iki farklı yük aralığındaki kuvvetlerde kullanılabilecek hava yayı karakteristiği çıkarılmıştır. Bu geliştirilen hava yaylarının kullanıldığ tasarımları ve imalatları yapılmıştır. Elde edilen sonuçlar çalışmanın eklem empedansının istenildiği gibi ve gerçek zamanlı değişebilen robotlarda kullanılmasının mümkün olduğudur. Fakat robotlarda uygulamak için SEA'nın tasarımının çok daha fazla iyileştirilmesi gereklidir.

Bu çalışmada nihai amacımız, bu aktüatörün dinamik davranışını test etmek ve değişen eklem empedans değerleri ile kendisine gelen darbelerin enerji olarak hangi oranlarda depolandığını test etmektir. $\mathrm{Bu}$ sayede de robotun farklı eklem hareketleri için aktüatörün davranışını ortaya koymaktır.

\section{Kaynaklar}

[1] Salisbury, K., Eberman, B., Levin, M., Townsend, W., The design and control of an experimental whole-arm manipulator, The Fifth International Symposium on Robotics Research, MIT Press, 233-241, (1991).

[2] Vanderborght, B., Albu-Schaeffer, A., Bicchi, A., Burdet, E., Caldwell, D., Carloni, R., Catalano, M., Ganesh, G., Garabini, M., Grioli, G., Haddadin, S., Jafari, A., Laffranchi, M., Lefeber, D., Petit, F., Stramigioli, S., Grebenstein, M., Tsagarakis, N., Van Damme, M., Van Ham, R., Visser, S., Wolf, S., Variable 
impedance actuators: moving the robots of tomorrow, IEEE/RSJ International Conference on Intelligent Robots and Systems, IROS 2012, (2012)

[3] Van Ham, R., Thomas, S., Vanderborght, B., Hollander, K., Lefeber, D., Compliant actuator designs: review of actuators with passive adjustable compliance/controllable stiffness for robotic applications, IEEE Robotics and Automation Magazine, 16(3), 81-94, (2009).

[4] Albu-Schaffer, A., Haddadin, S., Ott, C., Stemmer, A., Wimbock, T., Hirzinger, G., The DLR lightweight robot: design and control concepts for robots in human environments, Industrial Robot: An International Journal, 34(5), 376-385, (2007).

[5] $\mathrm{Xu}, \mathrm{Y} ., \mathrm{Au}, \mathrm{S}$., Stabilization and path following of a single wheel robot, IEEE/ASME Transactions on Mechatronics, 9(2), 407-419, (2004).

[6] K. Pullen, C. Ellis, Kinetic energy storage for vehicles, Hybrid Vehicle Conference, IET The Institution of Engineering and Technology, 2006, IET, 91-108, (2006).

[7] Petit, F., Albu-Schaffer, A., State feedback damping control for a multi DOF variable stiffness robot arms, IEEE International Conference on Robotics and Automation, ICRA 2011, 5561-5567, (2011).

[8] Albu-Schaeffer, A., Bicchi, A., Stramigioli, S., Burdet, E., Smagt, P., Parravicini, A., Lefeber, D., Tsagarakis, N., VIACTORS-variable impedance actuation systems embodying advanced interaction behaviors, European Future Technologies Conference, FET09, (2009).

[9] Arumugom, S., Muthuraman, S. ve Ponselvan, V., Modeling and application of series elastic actuators for force control multi legged robots, Journal of Computing, 1(1), 26-33, (2009).

[10] Rouse, E.J., Mooney, L.M. ve Martinez-Villalpando, E.C., Clutchable serieselastic actuator: design of a robotic knee prosthesis for minimum energy, 13th International Conference on Rehabilitation Robotics, ICORR, (2013).

[11] Vanderborght, B., Verrelst, B., Ham, R.V., Damme, M.V., Lefeber, D., Duran, B.M.Y. ve Beyl, P., Exploiting natural dynamics to reduce energy consumption by controlling the compliance of soft actuators, The International Journal of Robotics Research, 25(4), 343-358, (2006).

[12] Pratt, J.E., Exploiting inherent robustness and natural dynamics in the control of bipedal walking robots, Doktora Tezi, MIT (2000).

[13] Kawamura, A. ve Zhu, C., The Development of biped robot MARI-3 for fast walking and running, IEEE, (2006).

[14] Goris, K., Autonomous Mobile Robot Mechanical Design, (2005).

[15] Yesilevskiy,Y. ve Remy, C.D., Series or parallel elasticity - Which is better?, Dynamic Walking, (2014).

[16] Robinson, D.W., Pratt, J.E., Paluska, D.J. ve Pratt, G.A., Series elastic actuator development for a biomimetic walking robot, International Conference on Advanced Intelligent Mechatronics, Atlanta, (1999).

[17] Junior, A.G.L., de Andrade, R.M. ve Filho, A.B., Linear serial elastic hydraulic actuator: digital prototyping and force control, IFAC (International Federation of Automatic Control), (2015).

[18] Pratt, J.E. ve Krupp, B.T., Series elastic actuators for legged robots, Proc. SPIE 5422, Unmanned Ground Vehicle Technology VI, (2004).

[19] Pratt, J.E., Krupp, B.T. ve Morse, C.J., The RoboKnee: An exoskeleton for enhancing strength and endurance durin walking, IEEE International Conference on Robotics and Automation, New Orleans, (2004). 
[20] Pratt, G.A., Low Impedance walking robots, Integrative and Comparative Biology, 42(1), 174-181, (2002).

[21] Pratt, J., Krupp, B., Design of a bipedal walking robot, Proc. SPIE 6962, Unmanned Systems Technology X, Orlando, (2008).

[22] Robinson, D.W., Design and Analysis of Series Elasticity in Closed-loop Actuator Force Control, Doktora Tezi, MIT, Department of Mechanical Engineering, Massachusetts, (2000).

[23] Pratt, J., Legged Robots at MIT: What's new since raibert, IEEE Robotics \& Automation Magazine, 7(3), 15-19, (2000).

[24] Verrelst, B., Van Ham, R., Vanderborght, B., Lefeber, D., Daerden, F., VanDamme, M., Second generation pleated pneumatic artificial muscle and its robotic applications, Advanced Robotics, 20(7), 783-805, (2006).

[25] Tonietti, G., Schiavi, R., Bicchi, A., Design and control of a variable stiffness actuator for safe and fast physical human/robot interaction, IEEE International Conference on Robotics and Automation, ICRA 2005, 526-531, (2005).

[26] Schiavi, R., Grioli, G., Sen, S., Bicchi, A., VSA-II: a novel prototype of variable stiffness actuator for safe and performing robots interacting with humans, IEEE International Conference on Robotics and Automation, ICRA 2008, 21712176, (2008).

[27] Eiberger, O., Haddadin, S., Weis, M., Albu-Schäffer, A., Hirzinger, G., On joint design with intrinsic variable compliance: derivation of the DLR QA-joint, IEEE International Conference on Robotics and Automation, ICRA 2010, 1687-1694, (2010).

[28] Hurst, J.W., Rizzi, A.A., Series compliance for robot actuation: application on the electric cable differential leg, IEEE Robotics \& Automation Magazine 15(3), (2008).

[29] Topaç, M.M. ve Kurulay, N.S., Computer aided design of an anti-roll bar for a passenger bus, Mühendis ve Makina, 50, 594. (2009).

[30] Buzluk, S., Mekanik sistemlerde titreşim kontrolü, Yalıtım Kongresi, Eskişehir, (2001).

[31] Seyfarth, A., Geyer, H., Blickhan, R., Lipfert, S., Rummel, J., Minekawa, Y., Iida, F., Fast motions in biomechanics and robotics, Vol. 340, Springer, Berlin, Heidelberg, 383-401 (Chapter Running and walking with compliant legs), (2006).

[32] Tondu, B., Lopez, P., Modeling and control of mckibben artificial muscle robot actuators, IEEE Control Systems Magazine, 20(2), 15-38, (2000).

[33] Verrelst, B., Van Ham, R., Vanderborght, B., Lefeber, D., Daerden, F., Van Damme, M., Second generation pleated pneumatic artificial muscle and its robotic applications, Advanced Robotics, 20(7), 783-805, (2006).

[34] Villegas, D.C., Van Damme, M., Vanderborght, B., Lefeber, D., Third generation pleated pneumatic artificial muscles for robotic applications: development and comparison with McKibben muscles, Advanced Robotics, 26 1205-1227, (2012).

[35] De, A., Tasch, U., A two-DOF manipulator with adjustable compliance capabilities and comparison with the human finger, Journal of Robotic System, 13, 25-34, (1996).

[36] Akdas, D., An effective mechanical design and realization of a humanoid robot BUrobot, ACTA, Mechatronics, 11(10), (2014). 